\title{
Agroecosystem specific climate vulnerability analysis: application of the livelihood vulnerability index to a tropical highland region
}

\author{
Belay Simane • Benjamin F. Zaitchik • Jeremy D. Foltz
}

Received: 14 December 2013 / Accepted: 23 April 2014 / Published online: 4 July 2014

(C) The Author(s) 2014. This article is published with open access at Springerlink.com

\begin{abstract}
In topographically diverse highland terrain, socio-economic and environmental conditions can vary dramatically over relatively short distances. This presents a challenge for climate resilient development strategies, as exposure to climate variability and change, climate impacts, and adaptive capacity differ between communities located within common cultural and administrative units. The Livelihood Vulnerability Index (LVI) framed within the United Nations Intergovernmental Panel on Climate Change (IPCC) vulnerability framework (LVI-IPCC) offers a tool to assess climate vulnerability through direct household surveys. This makes it particularly appropriate for analyses at sub-community and community scales. Here we apply the LVI-IPCC to communities of Choke Mountain, located in the Blue Nile Highlands of Ethiopia. Recognizing the physiographic and climatic diversity that exists in this mountainous environment, we implement LVI-IPCC analysis for 793 mixed croplivestock farming households using the five distinct agroecological systems (AES) that compose the populated area of Choke Mountain as a framework for analysis. For each AES, an LVI index, adaptive capacity metric, and LVI-IPCC vulnerability score was calculated. We found that each of these metrics varied systematically across AES. High elevation sloping lands and low elevation steep lands exhibited relatively low adaptive capacity and high vulnerability while midland AES had higher capacity and lower vulnerability. These results suggest that resilience building interventions for Choke Mountain ecosystems should be targeted to address the specific circumstances of each AES. The approach of applying LVIIPCC at AES scale could be applicable to other climate vulnerable mountainous regions.
\end{abstract}

\footnotetext{
B. Simane $(\bowtie)$

College of Development Studies, Addis Ababa University, Addis Ababa, Ethiopia e-mail: simaneb@yahoo.com
}

Belay Simane

e-mail: belay.simane@aau.edu.et

B. F. Zaitchik

Department of Earth and Planetary Sciences, Johns Hopkins University, Baltimore, MD 21218, USA

e-mail: zaitchik@jhu.edu

J. D. Foltz

Agricultural and Applied Economics, University of Wisconsin-Madison, Madison, WI 53706, USA

e-mail: jdfoltz@wisc.edu 
Keywords Vulnerability $\cdot$ Adaptive capacity $\cdot$ Exposure $\cdot$ Climate change $\cdot$ Agroecosystem

\section{Introduction}

Ethiopia is frequently identified as a country that is highly vulnerable to climate variability and change (Parry et al. 2007; WorldBank 2010; Conway and Schipper 2011). At the national scale, vulnerability to climate is evident in economic and social sensitivity to interannual precipitation variability and extreme climate events, particularly drought (WorldBank 2011). These sensitivities are a product of large interannual climate variability and an economy that is highly dependent on agriculture (Byerlee et al. 2007) as well as institutional factors that can create socio-economic crises even in the absence of a large meteorological anomaly (Smakhtin and Schipper 2008). The combination of sensitivity to historic climate variability, limited capacity at institutional levels, and projections of significant future climate change are cause for concern that Ethiopia will be strongly and negatively impacted by changing climate patterns in the coming decades (McSweeney et al. 2010a, b; Ethiopian EPA 2011).

However, aggregated national statistics do not capture the complex distribution of vulnerabilities that is present at the local level. This is particularly true in the steeply dissected highland region that is home to a majority of the Ethiopian population. In this mountainous terrain, prevailing climate conditions and the sensitivity of agricultural systems to climate variability can change over a distance of even a few kilometers. Dramatic spatial heterogeneity is also seen in soil qualities, steepness of slope, and access to infrastructure to support transport, agricultural technologies, and capacity building. As a result, an estimate of vulnerability at the national, state or even district scale is inadequate to capture the full range of climate vulnerabilities within the Ethiopian highlands or to design effective resilience building interventions.

It should be noted that vulnerability in this context has been defined in a number of different ways (Gallopín 2006; Füssel 2007), and the outcome of any effort to quantify vulnerability will be sensitive to the choice of definition and metrics. Here we accept the general description of Kelly and Adger (2000), that vulnerability is the ability or inability of individuals or social groupings to respond to, in the sense of cope with, recover from, or adapt to, any external stress placed on their livelihoods and well-being. In the context of climate change, the Intergovernmental Panel on Climate Change (IPCC) adopts a variant of this definition, stated as "the degree to which a system is susceptible to, or unable to cope with, adverse effects of climate change, including climate variability and extremes" (IPCC 2007). In this definition, vulnerability is typically presented as a condition of three inter-related factors: exposure to impacts, sensitivity to impacts, and capacity to adapt to impacts (Snover et al. 2007).

The IPCC definition of vulnerability does not specify any particular assessment methodology or scale of analysis. One useful methodology for applying the definition at household and community levels is the Livelihood Vulnerability Index (LVI) adapted to the IPCC framework (LVI-IPCC; Hahn et al. 2009). The LVI-IPCC is an implementation of the Sustainable Livelihoods Approach to development analysis (Chambers and Conway 1992), according to which communities are described in terms of their natural capital, social capital, financial capital, physical capital, and human capital. Stresses related to climate change map onto each of these capitals, but climate exposures and adaptation actions are typically not explicitly considered in the approach. The LVI reorganizes the Sustainability Livelihoods Approach into new categories, which includes an explicit climate component, and is framed in a manner amenable to the use of household survey data. The LVI-IPCC, also developed by Hahn et al. (2009), maps the LVI components onto the three IPCC contributing factors to vulnerability-exposure, adaptive capacity, and sensitivity. 
In the first implementation of LVI-IPCC, Hahn et al. (2009) applied the methodology to two villages in Mozambique with differing socio-economic and environmental conditions. They found that one village was more constrained by a physical limitation-water resourceswhile the other had more severe socio-demographic vulnerabilities. The LVI-IPCC methodology has since been applied to study communities and regions in other parts of the developing world. Mohan and Sinha (2010), for example, applied the LVI-IPCC across districts in the Ganges River basin and found significant differences in vulnerability at a district level. Differences between districts were attributed to a number of factors, including relative degree of urbanization: more highly urbanized districts had greater adaptive capacity and therefore lower climate vulnerability. In a study of climate vulnerability in Northern Ghana, Entwire et al. (2013) applied the LVI-IPCC and found regional scale discrepancies in vulnerability, based in large part on access to water resources.

Climatically diverse regions, including the Ethiopian Highlands and many other tropical highland regions, present a challenge for policy-relevant implementation of the LVI-IPCC, simply because climatic and biophysical conditions change so dramatically over short distances. A critical question, and one that has not been addressed in the LVI-IPCC literature to date, is how to select a unit of aggregation that captures diversity across a climatically heterogeneous area while being generalizable enough to inform adaptation strategies beyond the specific communities surveyed in the study. Here, we use the agricultural ecosystem (AES) as the unit of analysis. This decision was made because the AES represents the intersection of (1) a set of agriculturally relevant climatic factors - i.e., the agroecological zone - with (2) soils and physiographic variables relevant to crop production, and (3) a prevailing set of cropping practices. As such, the AES is a relevant target for designing agriculture-oriented climate resilience strategies, and is therefore a critical unit for climate vulnerability analysis.

Applying an AES-based generalization to household-level analysis allows us to map vulnerability profiles across the landscape. This ability to generalize is critically important for adaptation planning, both because it makes it possible to exchange learning experiences across communities with similar vulnerability profiles and because it allows decision makers with broad geographic jurisdictions to understand patterns of vulnerability across relatively large areas.

\section{Choke Mountain}

Choke Mountain is located in the Blue Nile (Abay) Highlands region of Ethiopia (Fig. 1). The mountain's peak elevation is over $4,000 \mathrm{~m}$, but the edge of the mountain is defined in three directions by the Blue Nile gorge, where elevation drops to below 1,000 m. Over a distance of less than $70 \mathrm{~km}$, then, one finds hot, dry valleys, gently rolling, deep soiled midland plains, and cool, wet alpine zones. Complex topography creates strong local gradients in precipitation, temperature and soil properties, although rains are characteristically intense and erosive across topographic zones, and soils are deeply weathered and erodible over most of the mountain. The landscape is dominated by low-input mixed crop-livestock subsistence agriculture, with cultivation extending from the Blue Nile Gorge up to nearly the mountain's summit. The dominant crops are tef (Eragrostis tef), maize (Zea mays) and wheat (Triticum aestivum and T. Durum), while barley (Hordeum vulgare), potato (Solanum tubererosum), fava beans (Phaseolus vulgaris), chickpeas (Cicer arietinum), oat (Avena sativa), and sorghum (Sorhum bicolor Moench) are also grown in some parts of the mountain. Historically, the alpine zone surrounding Choke Mountain summit was covered in forest and natural grass- and shrublands, but increasing population and associated deforestation and land degradation have helped push the extent of cultivation to as high as 3,800 m elevation (Simane 2011). 


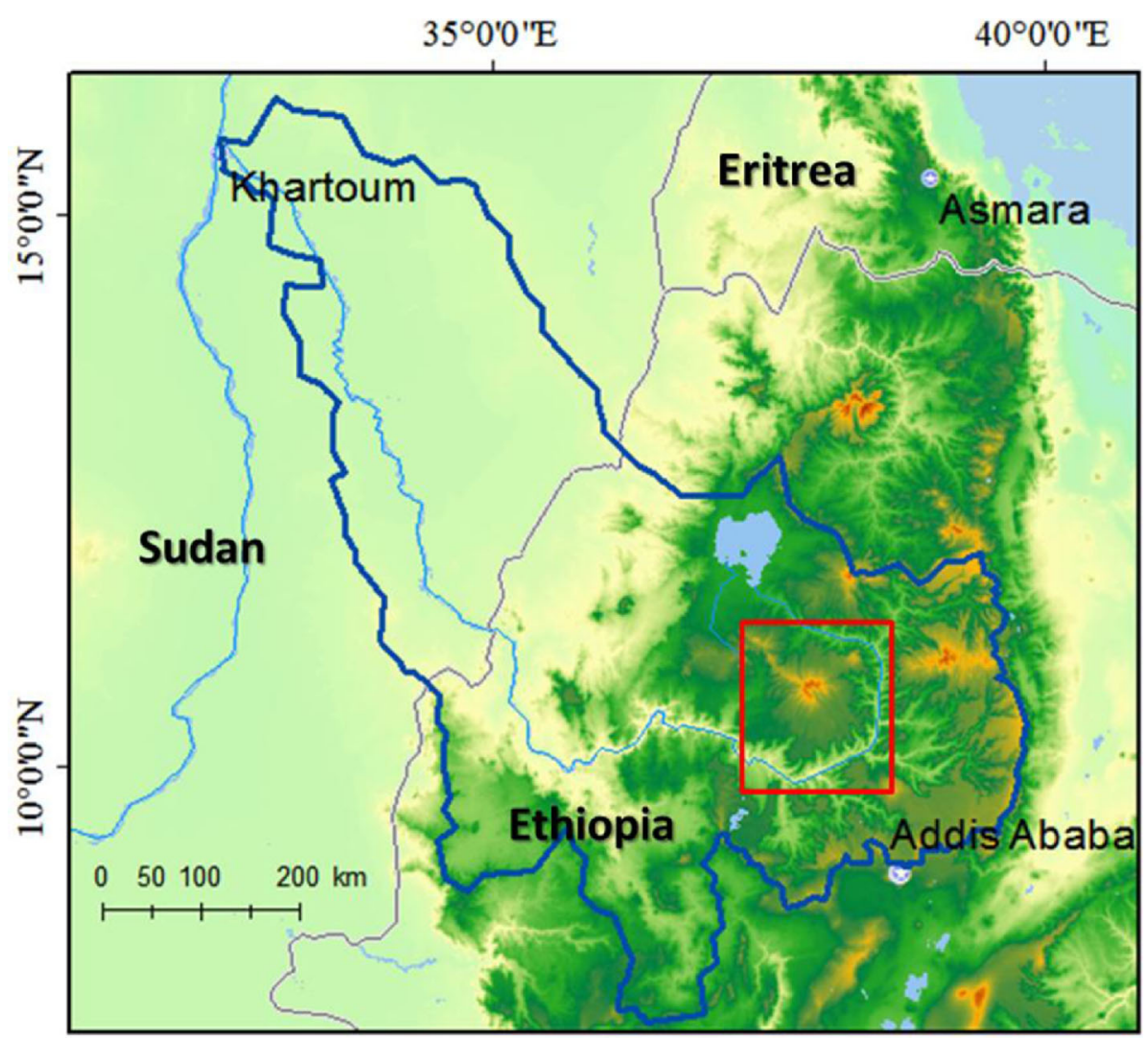

Fig. 1 Choke Mountain (red box) and the surrounding Blue Nile River basin (blue line)

Multiple sources of pressures on Choke ecosystems have taken a toll on the region's natural resources, with each posing its own management challenge. First, the natural resources base is under intense pressure from population growth and erosion-inducing traditional farming and management practices. Second, farming communities face severe constraints related to intensive cultivation, overgrazing and deforestation, soil erosion and soil fertility decline, water scarcity, and demand for livestock feed, and fuel wood. Third, climate change may already be contributing to these challenges. There has been a perceived increase in extreme rain events, and regional temperatures have exhibited an upward trend over the past 20 years (Simane et al. 2012). Together, these challenges have contributed to a documented decline in yields in some areas, and portions of the mountain have deteriorated from food surplus to food deficit areas within the past 20 years.

The Choke Mountain ecosystem is densely populated, with an average of 260-270 people per $\mathrm{km}^{2}$ (Simane 2011). Livelihoods are primarily dependent on subsistence mixed croplivestock agricultural systems, with very low inputs and outputs. There is no significant natural forest cover. The major natural habitats are moist moorland, sparsely covered with Giant Lobelia spp., Alchemilla spp., Festuca spp. and other grasses. Settlements are common up to about 3,600 m elevation, and extensive agricultural activity is found on steep slopes as well as on almost all gentle and moderately sloped land.

Under undisturbed conditions, soils on Choke Mountain tend to be deep - natural depths are thought to be more than $50 \mathrm{~cm}$ over most of the $\mathrm{BNH}$, with rooting depths up to one meter, allowing for local variability across terrain. These deep, weathered tropical soils are highly 
susceptible to erosion, and on lands cultivated using traditional methods the rate of soil loss can exceed the rate of soil generation by a factor of 4 to 10 (Hurni 1988). The process is exacerbated in large part by the prevalence of traditional criss-cross ox-drawn tillage systems that promote rapid erosion (Nyssen et al. 2000).

There is very little woody plant cover. Erica spp and Hypericum revolutum are found in patches. Arundinaria alpine is found both as a homestead plantation as well as part of the natural vegetation cover in the area, albeit very sparsely. Erithrina brucei is cultivated as a border demarcation plant in the area. Eucalyptus globulus is extensively gown as a plantation, and some of the residents of the area have become dependent on it for their livelihood.

Nutrient depletion is a serious problem in the region. Average soil loss rates on croplands have been estimated at $42 \mathrm{t} \mathrm{ha}^{-1} \mathrm{yr}^{-1}$ but may reach $300 \mathrm{t} \mathrm{ha}^{-1} \mathrm{yr}^{-1}$ in individual fields (Hurni 1998). High rates of on-field erosion are particularly problematic given that nutrients in Choke soils tend to be concentrated in the upper portion of the soil column. At present, soil acidity in the Choke is one of the major causes for land degradation. Nitosols and Acrisols that compose about $26 \%$ of the area are acidic, with $\mathrm{pH}<5$. At harvest, both grain and straw is removed from the field with no residue returned to the soil. The use of animal dung and crop residues as substitutes for household energy have further contributed to reduced soil fertility and agricultural productivity in the area. Nevertheless, the depth of the soil profile means that there are still significant soil resources, and experience indicates that productivity can be maintained and enhanced through effective field scale and landscape scale sustainable land management practices (Simane et al. 2012).

Considering physical, agricultural, and socio-economic factors, Simane et al. (2013) classified the Choke Mountain watersheds into six major agroecosystems (AES) using field-based agroecosystem analysis (Conway 1985) in combination with automated landscape classification (Fig. 2). The definition of AES was based on the overlay of three inputs: an agro-climatic zoning based on precipitation and temperature, a soil and terrain analysis, and a map of the distribution of farming systems. Simane et al. (2013) demonstrate that the AES show a remarkable degree of differentiation in terms of their defining constraints, opportunities, production orientation, and socio-economic characteristics of farmers. The classification provides a lens for vulnerability and adaptation analysis that considers the geographical differentiations as well as the socio-economic stratification of the agricultural sector of the study area. We note that only AES 1-5 are inhabited to any significant extent. AES 6 is the mountain summit, characterized by natural vegetation that is used commonly for grazing and as source fuel and construction wood. As there is no significant permanent population in AES 6 it is not included in LVI-IPCC analysis in this paper.

Observational studies have shown steady warming in Ethiopia since 1960 , at a rate of $\sim 0.28^{\circ} \mathrm{C}$ per decade (Conway and Schipper 2011). Climate models project continued warming for Ethiopia through the end of the 21 st century, with warming over the 20 th century baseline of $0.7-2.3^{\circ} \mathrm{C}$ for the $2020 \mathrm{~s}, 1.4-2.9^{\circ} \mathrm{C}$ for the $2050 \mathrm{~s}$, and $1.5-5.1^{\circ} \mathrm{C}$ for the $2090 \mathrm{~s}$, depending on global greenhouse gas emissions trajectories and the climate model used in the projection (Conway and Schipper 2011). Projections for precipitation are far more uncertain, both for Ethiopia in general (Conway and Schipper 2011) and for the Blue Nile Highlands specifically (Zaitchik et al. 2012). Studies that report the ensemble average of global climate model projections for all models participating in IPCC intercomparisons generally project an increase in precipitation by the end of the 21 st century, but the spread between models encompasses projections for both significant increase and substantial decrease in precipitation in the western part of the country.

Furthermore, changes in total precipitation might be less important to livelihoods in the region than changes in intensity, timing, and variability in precipitation. For example, some analyses project that the proportion of rainfall that falls in heavy precipitation events will increase throughout Ethiopia, with a particularly strong tendency during the July to September 


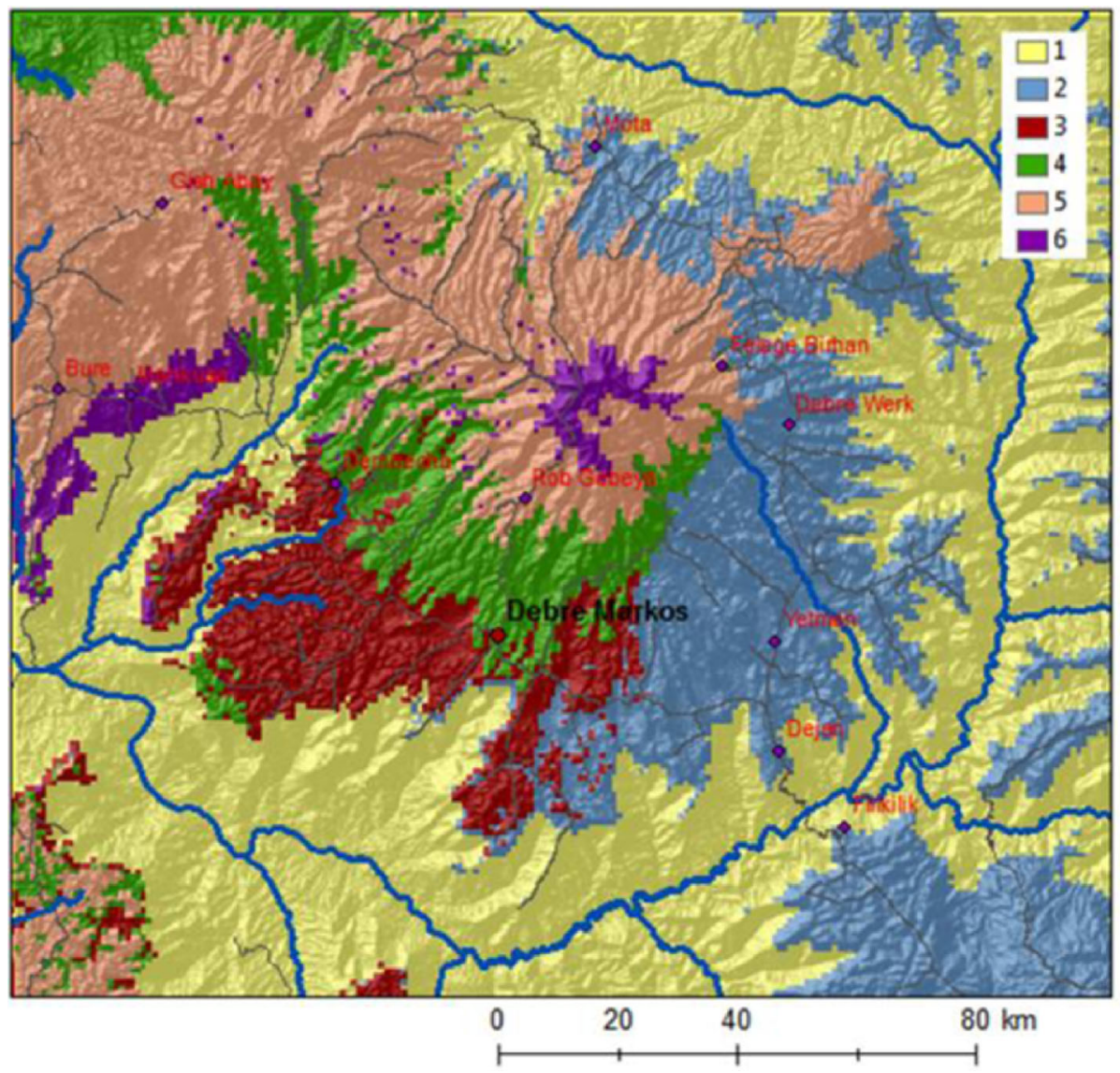

Fig. 2 The six major agroecosystems of Choke Mountain: lowland and valley fragmented agroecosystems (AES 1; total area 7,200 $\mathrm{km}^{2}$ ), midland plains with black soil (AES 2; 3,200 $\mathrm{km}^{2}$ ), midland plains with brown soils (AES 3; 1,600 km²), midland sloping lands (AES4; 1,300 $\mathrm{km}^{2}$ ), hilly and mountainous highlands (AES5; $2,400 \mathrm{~km}^{2}$ ), and Afro-alpine (AES6; $250 \mathrm{~km}^{2}$ ). Figure based on analysis from Simane et al. (2013)

rains that affect Choke Mountain (McSweeney et al. 2010a; b, Ethiopian EPA 2011). Both the frequency and intensity of droughts in Ethiopia have increased recently and inflicted severe damage to the livelihoods of millions of people. At the same time, increases in floods have stressed social institutions and intensified the vulnerability of households. A recent World Bank study projects that climate change will reduce Ethiopia's gross domestic product (GDP) growth by between 0.5 and $2.5 \%$ each year unless effective steps to build resilience are taken (WorldBank 2010).

\section{Methodology}

3.1 Defining vulnerability profiles and indicators for Choke Mountain

Hahn et al. (2009) developed and demonstrated the LVI and LVI-IPCC in an application to two villages in Mozambique. For their application, they defined seven major 
components of vulnerability that map onto the three IPCC contributing factors to vulnerability (exposure, adaptive capacity, and sensitivity). We adopt this framework for Choke Mountain but with some modification to the major components in order to match the conditions and constraints facing agricultural households in the Choke region. In place of the seven major components of Hahn et al. (2009) we define eight "profiles" related to vulnerability: climate, ecosystem, agriculture, wealth, technology, infrastructure, community, and social.

Each profile is defined by a set of indicators, and each has a hypothesized relationship with climate vulnerability. The indicators used here (Table 1) were developed based on a review of previous LVI studies in rural Africa and our earlier experience in the region. The definition of these geographically and culturally customized indicators is an important part of the LVI process. For Choke, it was important to consider changes in climate extremes along with changes in average temperature and precipitation, and it was also necessary to include indicators on ecosystems and landscape in addition to indicators on agricultural practices. For social capital, it was informative to include participation in existing community organizations and sustainable land management projects, as a large number of such organizations and projects are already active in the region. Under human capital, the sex of household head was deemed relevant because the cultural norm in the region is for female heads of households to rent their land rather than plowing it themselves; hence, the sex of head of household has a direct impact on the household's ability to utilize its property resources on account of plowing traditions, even though there is no inherent reason that sex of household head should impact human capital.

The eight vulnerability profiles were then mapped onto the three IPCC contributing factors to vulnerability in the same manner used in Hahn et al. (2009). Each of the profiles, with the possible exception of climate change, can also be associated with one of the five types of capital used in the Sustainable Livelihoods Approach (Chambers and Conway 1992) (Table 1).

\subsection{Household survey}

A cross-sectional survey was conducted from April to June, 2012 engaging 793 mixed croplivestock farming households in 36 communities spread across all 5 agroecosystems ( 87 in AES1, 183 in AES2, 148 in AES3, 284 in AES4, and 91 in AES5). The sampling method followed a stratified random sampling technique. The survey was conducted by development agents from local agriculture offices who were trained on the selection of households, timing and manner of conducting the survey and data recording. Verbal consent was obtained from each head of household.

The survey questions were designed to address the eight profiles used in calculating the LVI. They included inquiries on socio-economic and environmental attributes as well as questions related to farmers' perceptions of climate change and adaptation methods. The surveyed farmers were also asked questions about their observations regarding patterns of temperature and rainfall over the past 20 years. Household surveys were paired with biophysical survey to assess indicators related to land suitability and irrigation potential.

\subsection{Calculating the LVI}

The calculation of LVI follows the method used in Hahn et al. (2009) and Mohan and Sinha (2010). It is a balanced weighted average approach (Sullivan 2002) where each subcomponent contributes equally to the overall index even though each major component of different livelihood assets includes a different number of sub-components. 


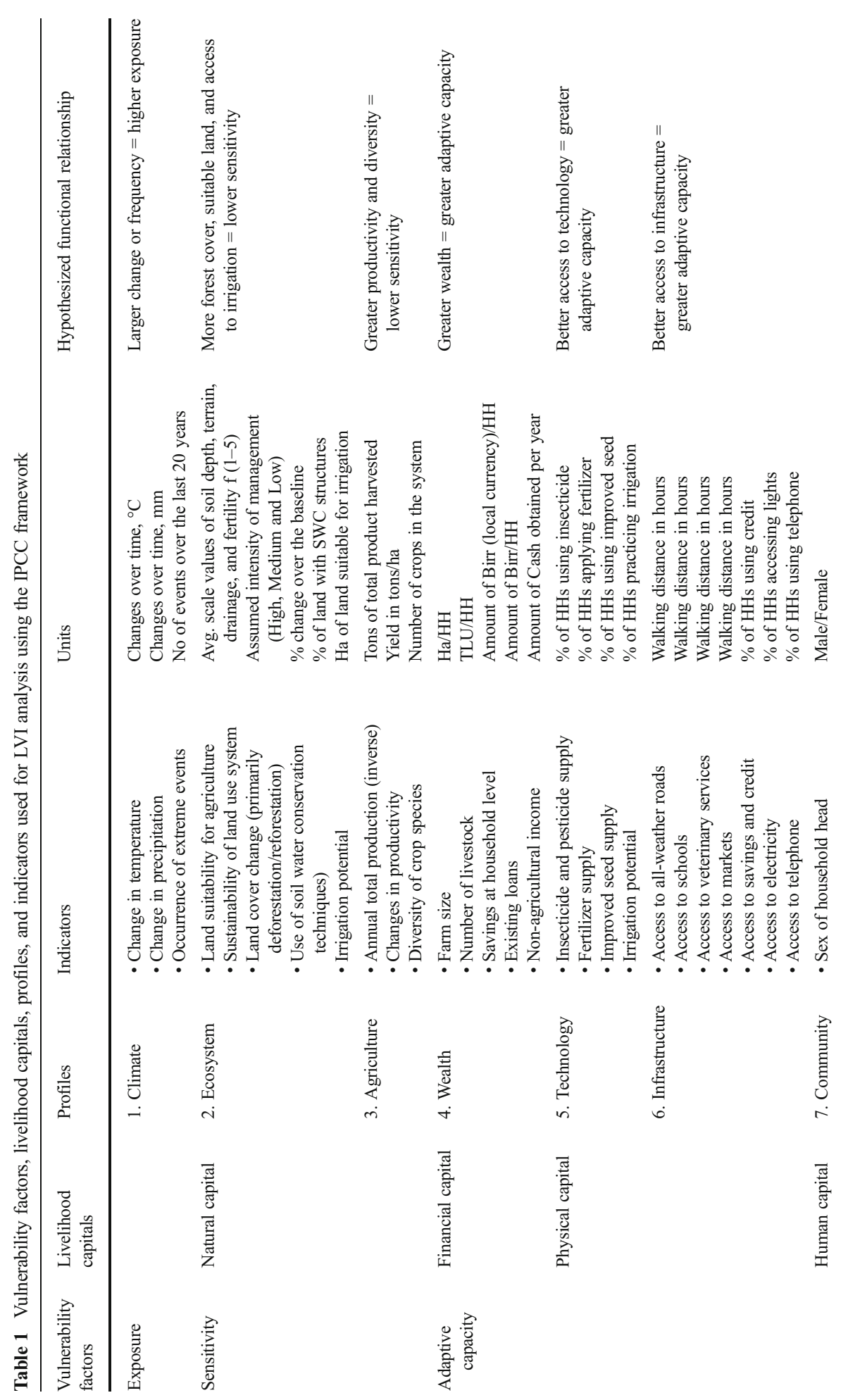




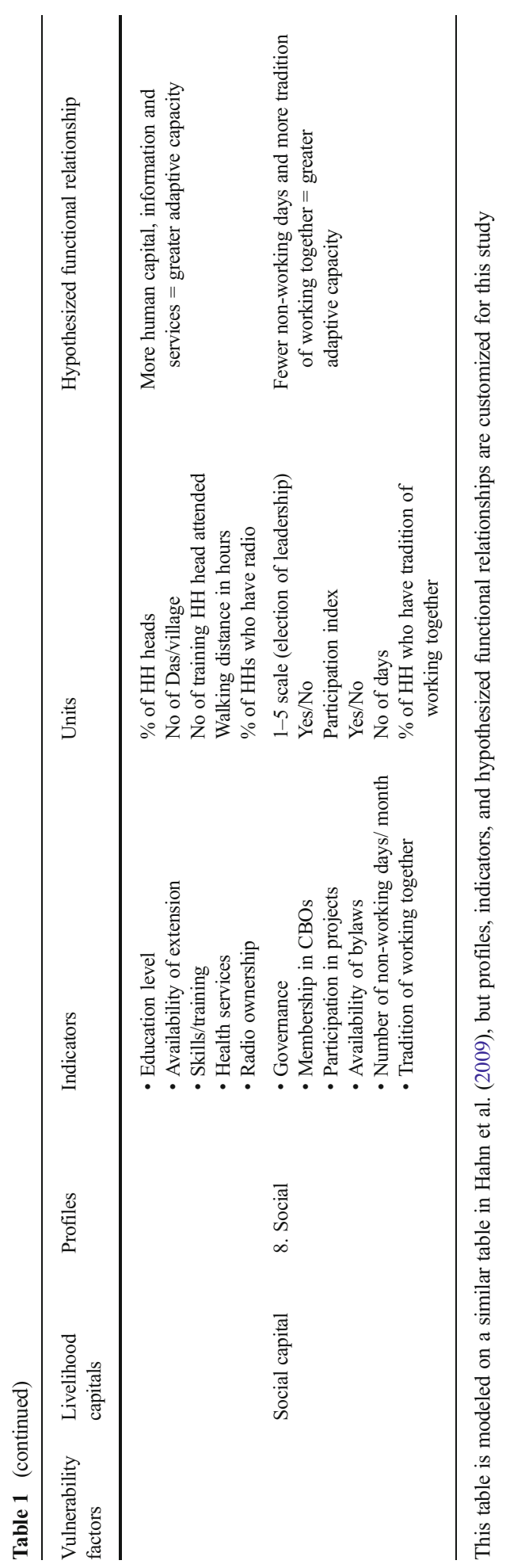


First, each indicator was standardized to a common scale:

$$
I_{v}=\frac{I_{a}-I_{\min }}{I_{\max }-I_{\min }}
$$

where $I_{v}$ is the standardized value for the indicator, $I_{a}$ is the value for the indicator $I$ for a particular $\operatorname{AES} a, I_{\min }$ is the minimum value for the indicator across all the AESs, and $I_{\max }$ is the maximum value for the indicator across all the AES. Next, a profile average value was calculated as:

$$
\boldsymbol{P}_{a}=\frac{\sum \boldsymbol{I}_{v}}{\boldsymbol{N}}
$$

where $P_{a}$ is the value for the profile in AES $a$ and $N$ is the number of variables in the profile. Values for each of the eight profiles were then combined to obtain the AES level LVI:

$$
L V I_{a}=\frac{\sum_{p=1}^{8} N_{p} P_{a, p}}{\sum_{p=1}^{8} N_{p}}
$$

where $\mathrm{LVI}_{\mathrm{a}}$ is the Livelihood Vulnerability Index for AES a and $\mathrm{N}_{\mathrm{p}}$ is the number of indicators in each profile.

The eight profiles are combined according to the IPCC categorization scheme as:

$$
C F_{a}=\frac{\sum_{p=1}^{f} N_{p} P_{a, p}}{\sum_{p=1}^{f} N_{p}}
$$

where $C F_{a}$ is an IPCC contributing factor (exposure $(E)$, sensitivity $(S)$, or adaptive capacity $(A)), f$ is the number of profiles associated with the contributing factor, and $p$ is indexed to the profiles associated with the $C F$. Finally, the LVI-IPCC for AES $a$ is calculated as:

$$
L V I-I P C C_{a}=\left(E_{a}-A_{a}\right) * S_{a} .
$$

The LVI-IPCC is scaled from -1 (least vulnerable) to 1 (most vulnerable) and is best understood as an estimate of the relative vulnerability of compared populations.

\section{Vulnerability index components}

In this section we provide an analysis of the key components used to generate the vulnerability index, highlighting the key components and where they differ between agro-ecosystems. Table 2 provides summary characteristics of the demographic and socioeconomic data for the study population, which falls under the index category of adaptive capacity-human capital. A total of 790 people participated in the study and of those studied, 737 (93\%) were male and $53(7 \%)$ were female. In terms of age category, the majority of respondents $(81 \%)$ are within the active working age group (31-65), while 32 respondents ( $4 \%$ ) are above 65 years of age. Seven hundred and thirty one respondents $(94 \%)$ were married and the remainder was single, divorced, or widowed. Education levels are low with many of the respondents ( $45 \%$ ) being illiterate, approximately $52 \%$, were either able to read and write or had primary education (1-4 years schooling), and only $2.3 \%$ of the respondents having attended secondary school.

\subsection{Exposure profile: climate change}

Active adaptation to climate change requires that farmers first notice that the climate has changed and that they then identify useful adaptation options and implement them (Maddison 2006; Sewagegn 2011). People living in different agro-ecological systems are believed to perceive 
Table 2 Characteristics of the study population $(n=793)$

\begin{tabular}{llr}
\hline Characteristics & Category & $\%$ \\
\hline Gender & Male headed households & 93.3 \\
& Female-headed households & 6.7 \\
Age & $15-30$ & 15.2 \\
& $31-65$ & 80.7 \\
Marital status & $>65$ & 4.1 \\
& Married & 94.3 \\
& Not married & 1.7 \\
Education & Divorced & 4.0 \\
& Illiterate & 45.1 \\
& Reading and writing & 42.2 \\
& Primary school & 10.1 \\
& Secondary school & 2.7 \\
\hline
\end{tabular}

climate change differently, even when the systems are in close proximity to one another, due to contrasts in local climate impacts, as well as to differing socio-economic perspectives on these impacts (Simane et al. 2012). From our random sample data we are able to assess farmer perceptions of climate change and how they vary across agro-ecosystems, with the results shown in Table 3. These measures fall under the LVI-IPCC category Exposure-Climate.

In terms of temperature changes, about $85 \%$ of the respondents perceived that the temperature has increased over the last 20 years. This perception is significantly different from zero in all agro-ecosystems, and is also is significantly different, at a $95 \%$ confidence level, in its intensity between agro-ecosystems. ${ }^{1}$ The strongest impression of increasing temperatures is in AES1 and AES3, $95 \%$, which is significantly greater (at a $95 \%$ level) than in the other three zones, which are not statistically different from each other. This perception is consistent with scientific temperature measurements for Choke Mountain, which show linear trends in average monthly maximum temperature on the order of $0.03{ }^{\circ} \mathrm{C}$ per year, or $\sim 0.3{ }^{\circ} \mathrm{C}$ per decade, since 1979, at stations located at low elevation, medium elevation, and high elevation (Fig. 3a).

Perceptions of precipitation change, with an average value of $61.3 \%$ perceiving a decrease in rainfall, however, differed less significantly across agro-ecological zones. Only AES 3 with $55 \%$ seeing a decrease in rainfall is significantly different at a $95 \%$ level from AES 1 and AES 2, while AES 4 and AES 5 are not statistically significantly different from any of the other zones. The big difference to note is that in AES 3 relative to the other agro-ecosystems a much greater percentage, $31 \%$, thought that there was a change in the timing (seasonality) of the rainfall rather than a decrease in rainfall. In terms of extreme weather events, $85.8 \%$ of farmers claimed to have been hit by an "extreme weather event or hazard related to climate change", with the AES 5 zone showing the highest level at $95.6 \%$, which was statistically greater than all the other zones except AES 4. This shows the farmers at the highest altitudes being more vulnerable to extreme weather events than those at lower altitudes, AES 1, 2 and 3.

These responses from farmer perceptions show that across all agro-ecosystems farmers on average perceive an increase in temperatures and decreases in precipitation. The relatively wide variation in perceptions across agro-ecosystems is understandable given the significant temporal and spatial variability in precipitation on Choke Mountain. It is interesting that a plurality of

\footnotetext{
${ }^{1}$ Here and in future uses of the term "significantly different" in this document we mean that a statistical test of difference in means is significant at a $95 \%$ confidence level for a two tailed t-test.
} 
Table 3 Perceptions of climate change over the past 20 years, as reported in household surveys. All values are percent of responses in the given AES

\begin{tabular}{|c|c|c|c|c|c|c|}
\hline & AES1 & AES2 & AES3 & AES4 & AES5 & All households \\
\hline \multicolumn{7}{|l|}{ Temperature } \\
\hline Increasing & 95.2 & 78.3 & 94.6 & 79.6 & 80.2 & 85.5 \\
\hline Decreasing & 2.4 & 14.1 & 3.4 & 18.6 & 12.1 & 10.1 \\
\hline No change / constant & 2.4 & 1.6 & 0.7 & 0.9 & 3.3 & 1.8 \\
\hline I don't know & 0.0 & 5.4 & 1.4 & 0.0 & 4.4 & 2.2 \\
\hline $\begin{array}{l}\text { Significantly different ( } 95 \% \text { level) } \\
\text { from AES }\end{array}$ & $2,4,5$ & 1,3 & $2,4,5$ & 1,3 & 1,3 & \\
\hline \multicolumn{7}{|l|}{ Precipitation } \\
\hline Increasing & 8.3 & 13.0 & 2.7 & 0.9 & 5.5 & 6.1 \\
\hline Decreasing & 65.5 & 56.0 & 54.7 & 69.9 & 60.4 & 61.3 \\
\hline No change & 4.8 & 1.6 & 1.4 & 1.8 & 1.1 & 2.1 \\
\hline Change in seasonality & 10.7 & 23.4 & 31.1 & 23 & 27.5 & 23.1 \\
\hline Increased drought frequency & 9.5 & 3.8 & 7.4 & 3.5 & 3.3 & 5.5 \\
\hline I don't know & 1.2 & 1.1 & 2.7 & 0.9 & 2.2 & 1.6 \\
\hline $\begin{array}{l}\text { Significantly different ( } 95 \% \text { level) } \\
\text { from AES... }\end{array}$ & 3 & 3 & 1,2 & None & None & \\
\hline \multicolumn{7}{|l|}{ Extreme events } \\
\hline $\begin{array}{l}\text { Did you experience extreme weather } \\
\text { events or climate hazards }\end{array}$ & 78.3 & 85.0 & 58.3 & 85.7 & 69.0 & 74.4 \\
\hline Significantly different (95\% level) from AES... & 5 & 5 & 5 & None & $1,2,3$ & \\
\hline
\end{tabular}

farmers perceived a decrease in precipitation when most measurements suggest no change or a small increase. In fact trends in precipitation are not statistically significant over most of the mountain (Fig. 4a; significance calculated using 2-tailed Student's t-test for linear trend). Some changes in timing - an increase in early rainy season precipitation on southern slopes of the mountain and a reduction in late season precipitation at the end of the rainy season (Figs. 4b, c) have been observed, however, which is a trend identified by about a quarter of the farmers. As indicated in all panels of Fig. 4, objectively measured trends in precipitation total and timing have differed for different parts of the Mountain. These farmer perceptions being at odds with a number of the objective measures might reflect a climatic signal - if precipitation is steady but temperature rises, water stress may increase, thus giving the perception of a precipitation shortfall — or it might reflect a tendency to attribute a range of hardships relating to land use pressure, land degradation, and economic pressures to a lack of rain.

\subsection{Sensitivity profiles: ecosystems and agriculture}

In previous studies we have reported on the agricultural suitability (Simane et al. 2012) and biophysical constraints on productivity (Simane et al. 2013) for each of the Choke Mountain AES. These studies found highest agricultural potential in the midland AES (AES 2 and AES 3 ), which are characterized by relatively gentle slopes and productive soils. Suitability is lower in AES 4 and AES 1, which are affected by acid, low fertility soils, and steep slopes with shallow soils, repsectively. AES 5 has very low suitability due to a combination of steep slopes and shallow, low fertility soils. Land degradation due to erosion is greatest in AES 1 and AES 5 and is moderately high in AES 4. The primary causes of enhanced erosion in these AES are deforestation and the use of traditional ox-drawn plows on steep slopes. 


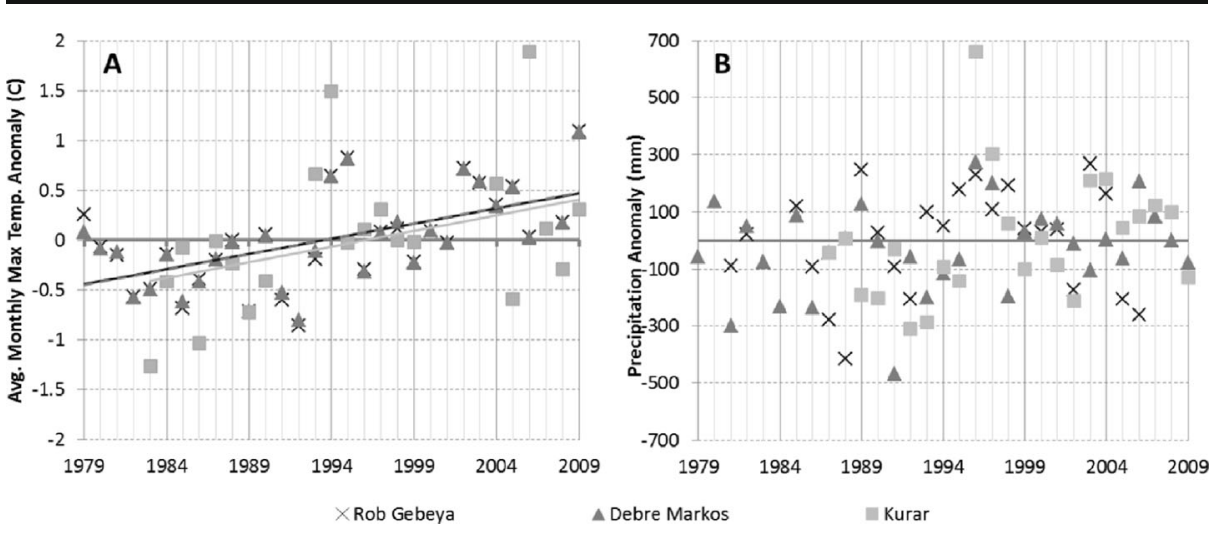

Fig. 3 Meteorological station records of (a) annually averaged monthly maximum temperature anomaly and (b) annual precipitation anomaly for Rob Gebeya (AES5), Debre Markos (AES3/4) and Kurar (AES1). Linear trends in (a) are significant at $p<0.05$ for Debre Markos (gray dashed line; $\mathrm{t}$-stat $=3.9, p=0.00057, d f=29$ ) and Rob Gebeya (black dashed line; $\mathrm{t}-\mathrm{stat}=3.6, p=0.0011, d f=29$ ) and at $p<0.1$ for Kurar (solid light gray line; $\mathrm{t}$-stat $=$ $1.89, p=0.074, d f=21$ ) using a Student's t-test for linear trends over the period of record. For all three stations the slope of the trendline is $\sim 0.3{ }^{\circ} \mathrm{C}$ per decade. The same statistical analysis indicated that there are no statistically significant linear trends for data shown in (b)

Land degradation has become one of the most important environmental problems on Choke Mountain, mainly due to soil erosion and nutrient depletion. Coupled with poverty and the fast-growing population, land degradation poses a serious threat to national and household food security. In order to reduce soil erosion, a number of soil conservation technologies have been introduced including physical measures (terracing and small check dams), fallowing, and plowing horizontally to the slope. Physical soil and water conservation (SWC) measures have been exercised by $34.9 \%$ of the respondents (Table 4), with some significant variations between zones (AES 1 at $46 \%$ is significantly higher than AES 2 at $25 \%$ ). However, efficiency of soil conservation structures (SCS) has been low in high rainfall areas of Ethiopia mainly due to crop yield reductions, increased soil erosion following breaching of SCS, and incompatibility with the tradition of cross-plowing and water-logging behind SCS (Simane 2011). Meanwhile the use of fallowing and avoiding crisscross plowing have been taken up by only a small minority of farmers, do not show much variation between agroecosystems and is therefore not included in the LVI-IPCC index.
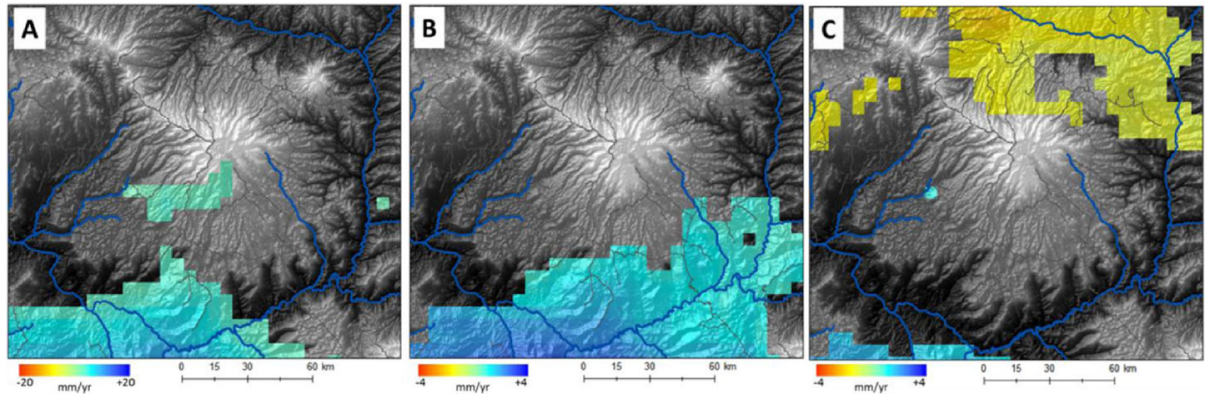

Fig. 4 Trends in precipitation calculated for the period 1981-2012 using the USGS Climate Hazard Group InfraRed Precipitation with Station (CHIRPS) merged gauge and satellite product (Funk et al. 2013). Only trends significant at $p<0.1$ (two-tailed student's t-test for linear trend, $d f=31$ ) are shown for a annual, b June, and c September precipitation. Gray shading shows topography 
Table 4 Land management practices and land fertility status, as reported in household surveys. All numbers are percent of responses within the given AES

\begin{tabular}{|c|c|c|c|c|c|c|c|}
\hline & Measure & AES1 & AES2 & AES3 & AES4 & AES5 & All households \\
\hline Sustainable land management & Physical SWC & 46.4 & 25.0 & 37.8 & 36.0 & 36.3 & 34.9 \\
\hline $\begin{array}{l}\text { Significantly different } \\
\text { (95\% level) from AES... }\end{array}$ & & 2 & 1 & None & None & None & \\
\hline \multirow[t]{3}{*}{ Land productivity } & Increased & 39.5 & 37.6 & 32.0 & 24.3 & 18.0 & 33.3 \\
\hline & Decreased & 55.6 & 59.4 & 63.3 & 62.1 & 75.3 & 62.6 \\
\hline & No change & 4.9 & 2.9 & 3.6 & 6.7 & 6.7 & 4.1 \\
\hline $\begin{array}{l}\text { Significantly different } \\
\text { (95\% level) from AES... }\end{array}$ & & 5 & 5 & 5 & 5 & $1,2,3,4$ & \\
\hline
\end{tabular}

Table 4 also shows that farmers generally perceived decreased productivity on their farmlands. While $33 \%$ of the total population has reported that land productivity has increased, the majority, $63 \%$, have reported that land productivity has decreased over the last 20 years due to land degradation, rainfall variability, drought and pests. The largest decrease in perceived land productivity, at $75 \%$, is in AES5, which is statistically different than AES 1,2 , and 4, while AES 3 falls in between the other zones and is not statistically different from them.

4.3 Adaptive capacity profiles: wealth, technology, infrastructure, community and social capital

As shown in Table 5, across all five AES, the average land holding is 1.2 ha, with $94.3 \%$ of the farmers owning their land. Among respondents, $50 \%$ report that their land holding size has decreased over the past 20 years for reasons that include redistribution and land degradation, while $9 \%$ have reported an increase in agriculturally useable land holdings as a result of clearing forest lands and grazing areas and redistribution of land. AES 3 and AES 4 stand out as having statistically significantly larger average land holding size, although the difference of a tenth of a hectare is small. In all agro-ecosystems farm sizes decreased on the majority of farms in all except AES 3 where only a third of the farms

Table 5 Land and livestock holdings for each agro-ecosystem, as reported in household surveys

\begin{tabular}{|c|c|c|c|c|c|c|c|}
\hline & & AES1 & AES2 & AES3 & AES4 & AES5 & Average \\
\hline $\begin{array}{l}\text { Land ownership (not significantly } \\
\text { different) }\end{array}$ & & 95.2 & 91.3 & 97.3 & 93.7 & 95.6 & 94.3 \\
\hline Average land holding size & (ha) & 1.0 & 0.97 & 1.23 & 1.28 & 1.1 & 1.15 \\
\hline $\begin{array}{l}\text { Significantly different (95\% level) } \\
\text { from AES... }\end{array}$ & & 4 & 3,4 & 2 & 1,2 & None & \\
\hline \multirow{3}{*}{$\begin{array}{l}\text { Changes in farmland size over the } \\
\text { last } 20 \text { years (not significantly } \\
\text { different) }\end{array}$} & Increased & 11.1 & 4.0 & 11.6 & 12.6 & 10.0 & 8.8 \\
\hline & Decreased & 58 & 52.5 & 36.3 & 55 & 61.1 & 48.8 \\
\hline & No change & 30.9 & 43.5 & 52.1 & 32.4 & 28.9 & 42.4 \\
\hline Possession of livestock & TLU & 1.26 & 1.56 & 1.13 & 2.16 & 1.45 & 1.63 \\
\hline $\begin{array}{l}\text { Significantly different (95\% level) } \\
\text { from AES... }\end{array}$ & & 4 & 4 & 4,2 & $1,2,3,5$ & 4 & \\
\hline
\end{tabular}

All figures are $\%$ of farmers within the given AES, except for average land holding size which is hectares $T L U$ Tropical Livestock Unit 
decreased in size. None of these differences in farmland changes, however, were statistically significantly different.

In quantifying livestock resources we aggregated all animals owned by farm households using tropical livestock units (TLU) (Jahnke and Asemanew 1983), and find that AES 4 has a statistically significantly higher level of livestock ownership than all other zones. The differences between AES 4 and the others imply major differences in livestock holdings and therefore wealth levels. For example, the difference in tropical livestock units between AES 4's, 2.2 TLUs and AES 1's 1.3 TLUs is the equivalent of a household in AES 4 having an extra two sheep and one cow. Households in the midland AES 3 also have significantly fewer livestock than AES 2 and 4, due in part to land pressures.

Differences in technology profiles between AES were attributed primarily to differences in the use of chemical fertilizer and improved seed as well as irrigation potential. The percentage of farmers who have applied chemical fertilizers across all AES in the Choke mountain area is high by Sub-Saharan Africa standards, with an average of $78 \%$ having used chemical fertilizer. There exists, however, statistically significant differences between agro-ecosystems in fertilizer use with AES 5 at $50 \%$ statistically significantly lower than all the other AES except for AES 1, which is at $64 \%$. Fertilizer use is correlated with livestock ownership $(0.148, p$-value $=0.000)$, suggesting that access to sources of wealth partially constrains farmers from using fertilizer. In addition, the total amount of chemical fertilizer applied is low, even among farmers that report using some fertilizer.

Irrigation use, the percentage of farmers with some irrigation on their land, varies between agroecosystems with an average of $20 \%$ of the farms having some irrigation, while AES2's $10 \%$ average is statistically significantly below the overall average and that of AES3, 4, and 5. This difference primarily reflects drainage characteristics, as AES2 soils are prone to water-logging; irrigation could be useful in targeted seasons and years, but without adequate investment in drainage it is unlikely to be economically effective. On average, $16 \%$ of farmers use improved seeds, with significant variation across agro-ecosystems. AES 5 has a statistically significantly lower level of improved seed use, $4 \%$, than all other zones. Meanwhile AES 1, 2 and 4 with rates between 19 and $22 \%$ are statistically significantly greater than the rate of improved seed use in AES 3 of $10 \%$. In general, use of improved varieties in the midland agro ecologies of cool sub-moist mid-highlands, cool moist mid-highlands, and temperate moist mid-highlands is higher than in the extreme very cold sub-moist mid-highlands.

Access to major indicators of infrastructure (i.e., access to road, first cycle primary school, veterinary services, market, credit institution, electricity, and telephone; Table 6) are comparable to national average figures and do not vary significantly across agro-ecosystems. The majority of the human capital profile measures were provided in Table 2 . In addition it is worth noting that $99 \%$ of the households have access to agricultural extension and health services within $5 \mathrm{~km}$ of their homes a figure that does not vary significantly across agro-ecosystems. Social capital measures varied little and without statistical significance between agroecosystem and are omitted for brevity.

\section{Livelihood vulnerability index}

Combining the measures in Table 1 using the methodology in Eqs. (1)-(5) provides a measure of the LVI-IPCC index for the five agro-ecosystems in the Choke mountain area. The results produce measures of exposure, sensitivity, and adaptive capacity, which all differ systematically across AES (Table 7). As is evident from the calculation of LVI-IPCC (Eq. 5), high values of exposure relative to adaptive capacity yield positive vulnerability scores while low values of 
Table 6 Access to major indicators of infrastructure within $5 \mathrm{~km}$ of the home, as reported in household surveys

\begin{tabular}{ll}
\hline Indicator & Proportion of farmers with access (\%) \\
\hline Road & 63 \\
Primary school & 99 \\
Veterinary services & 73 \\
Market & 95 \\
Credit institutions & 85 \\
Electricity & 42 \\
Telephone & 65 \\
\hline
\end{tabular}

exposure relative to adaptive capacity yield negative vulnerability scores. Sensitivity acts as a multiplier, such that high sensitivity in an AES for which exposure exceeds adaptive capacity will result in a large positive (i.e., high vulnerability) LVI-IPCC score. For Choke Mountain, exposure is high and adaptive capacity low for AES 1 and AES 5. This results in positive LVIIPCC scores, which we classify here as "highly vulnerable" since it indicates an adaptation capacity deficit and high exposure relative to other AES. The opposite is true for AES 2 and AES 3, in which adaptive capacity exceeds exposure and overall vulnerability is deemed to be low. AES 4 exhibits intermediate vulnerability: the LVI-IPCC score is positive, but it is close to zero. The wealth, technology and infrastructure profiles are strong determinants of vulnerability. The community profile was another determinant, but, with fewer differences amongst the different agro-ecosystems, it played a secondary role. The social profile was not a major factor as there were few significant differences amongst the agro-ecosystems.

Put in geographic context, these results of estimating the LVI-IPCC index suggest that $30 \%$ of the total land mass (midland plains with black soil (AES 2) and midland plains with brown soils (AES 3)) has relatively low vulnerability to climate change (Fig. 5). Overall, $62 \%$ of the total land mass is categorized as having high relative vulnerability. This includes the lowland, valley fragmented AES 1 and the mountainous highland AES 5. With $8 \%$ of the land mass - the midland sloping lands (AES 4) - is moderately vulnerable. The mountain summit is not classified on this map because there is no permanent population for LVI analysis, but it is known to have low agricultural potential and high susceptibility to overgrazing and deforestation (Simane et al. 2013). As this AES is largely uninhabited, however, it was not possible to include it in the formal LVI-IPCC analysis.

\section{Conclusions and recommendations}

The LVI-IPCC offers a framework to evaluate and understand relative climate change vulnerability at household to community level in the Choke Mountain area, located in the Blue Nile

Table 7 Calculated indices for contributing factors and the Livelihood Vulnerability Index under the LVI-IPCC framework

\begin{tabular}{llllc}
\hline & Exposure & Sensitivity & Adaptive capacity & LVI-IPCC \\
\hline AES 1 & 0.78 & 0.30 & 0.21 & 0.72 \\
AES 2 & 0.30 & 1.26 & 0.73 & -0.62 \\
AES 3 & 0.30 & 1.31 & 0.78 & -0.72 \\
AES 4 & 0.60 & 0.94 & 0.45 & 0.18 \\
AES 5 & 0.76 & 0.21 & 0.25 & 0.71 \\
Average & 0.55 & 0.80 & 0.48 & 0.05 \\
\hline
\end{tabular}




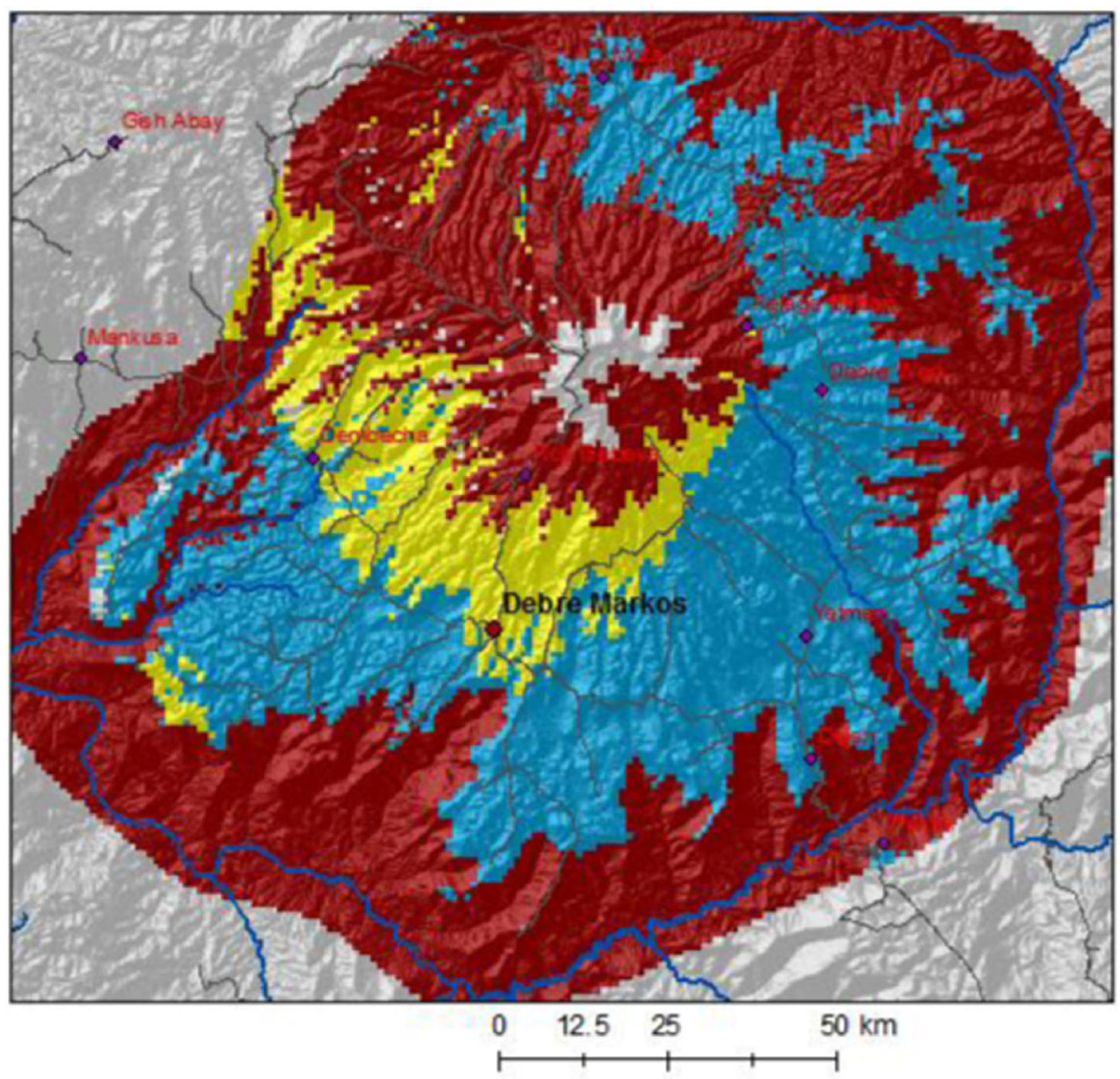

Fig. 5 Relative Vulnerability Index for each AES on Choke Mountain. Red = highly vulnerable; yellow = moderately vulnerable; blue = less vulnerable. The map is cropped at the Blue Nile gorge to avoid extrapolation to areas that were not included in household survey. AES 6, the mountain summit, is also excluded from analysis

Highlands region of Ethiopia. As this mountainous region is characterized by significant physiographic and climatic diversity, we applied LVI-IPCC at the scale of the agroecological system (AES) - a unit of aggregation that captures much of the physical, agricultural, and social diversity of the mountain. For Choke Mountain, the LVI-IPCC analysis indicated that lowland and the extreme highland AES have the highest perceived exposure to climate stresses and the most limited adaptive capability. This combination makes communities in these AES particularly vulnerable to climate change. Midland AES, in contrast, have lower perceived exposure and greater adaptive capacity, such that their climate vulnerability is relatively low. The process of performing the LVI-IPCC revealed a number of farmer-perceived constraints on productivity and stresses related to changing environmental conditions, which is useful for interventions in these low vulnerability but still relatively poor areas. For the most vulnerable AES the LVIIPCC identifies particular adaptation barriers that can be targeted in future interventions, specifically lack of access to new technologies in the most vulnerable agro-ecosystems. Interestingly, basic infrastructure, education, access to markets, and extension services did not differ across AES, suggesting that the infrastructure backbone required to improve adaptive capacity is evenly distributed for the majority of communities on Choke Mountain. 
The LVI-IPCC vulnerability analysis of Choke Mountain is now being used to inform community-driven climate resilience building strategies at "Climate Innovation Platforms" that have been established in select communities in all AES (Simane et al. 2012). Vulnerability analysis was an essential step in this process, as effective adaptation must be based on a solid understanding of local vulnerability, including adaptive capacity alongside exposure and sensitivity. This is an important consideration as the Climate Innovation Platforms model piloted on Choke Mountain is extended to other parts of Ethiopia, and perhaps beyond.

As with any generalization, AES-based analysis necessarily simplifies intra-community and temporal variability in vulnerability profiles (Smit and Wandel 2006; Swanson et al. 2009). Nevertheless, the systematic differences in LVI-IPCC observed between AES do indicate that the AES captures meaningful differences in vulnerability across the landscape of the study region. The method could be usefully applied to study landscape-scale vulnerability patterns across other tropical highland regions in a comparative perspective.

Finally, we emphasize that climate change is only one of the many challenges facing subsistence agricultural communities of Choke Mountain. Therefore, climate change adaptation must be advanced as a component of a holistic effort to build resilience of communities to the range of shocks and stresses that they experience. In this regard Choke Mountain is typical of subsistence agricultural regions throughout the tropics, and the LVI-IPCC analysis is best understood as a climate-oriented lens directed at the broader challenge of sustainable development.

Acknowledgments A portion of this research was supported in part by Addis Ababa University and by NSFCNH GEO-1211235

\section{Appendix: household survey (English translation)}

Household survey

\section{Introduction}

This study is being carried out by Addis Ababa, John Hopkins and Wisconsin Universities to collect basic information/data about Community-based Innovation Platforms (CIPs) in the Choke Mountains' watersheds and assess the problems of the surrounding communities to plan for sustainable adaptation and development activities.

The objective of this questionnaire is to collect primary data on socio-economics, ecologicy, and development that are required to assess the sustainability and effectiveness of established CIPs. Therefore, you are kindly requested to give your response freely and accurately to ensure the success of this study.

Dear respondents: You should be confident that the data/information which you give us works only for this study and the development of the target community.

Lastly, I thank you for your cooperation

Name of data collector Date Code

AES:

Wereda:

Kebele 


\section{Socioeconomic Characteristics}

1. House Code

2. Sex $1=$ Male $2=$ Female

3. Age $1=<15$ (child headed family) $2=15-30 \quad 3=31-65 \quad 4=>65$

4. Religion $1=$ Christian orthodox $2=$ Muslim $3=$ Protestant $4=$ Other

5. Marital Status $1=$ married $2=$ not married $3=$ divorce $4=$.

6. Educational Status $1=$ illiterate $2=$ capable of reading and writing $3=$ primary school $4=$ secondary school or above

7. Responsibility in the community $1=$ member of the community $2=$ religious leader $3=$ coordinator of community development work $4=$ Kebele Administrator $5=$ other, please specify

8. Size of family

\begin{tabular}{|c|c|l|l|l|}
\hline \multirow{2}{*}{ No } & Age & \multicolumn{3}{|c|}{ Sex (in number) } \\
\cline { 3 - 5 } & & Male & Female & Total \\
\hline 8.1 & $<14$ year & & & \\
\hline 8.2 & $15-65$ years & & & \\
\hline 8.3 & $>65$ year & & & \\
\hline & & & & \\
\hline
\end{tabular}

\section{Land}

1. $\begin{array}{lll}\text { Do you have your own farm land } & 1 \text {. Yes } \quad 2 \text { No }\end{array}$

2. If your answer for question 1 is yes, what is its size in hectare or (Timad)?

- Cultivated land

- Grass and woodland

- Forest land

- Homestead

- Irrigated Land TOTAL

3. Has your farm land size decreased or increased since you started farming?

$\begin{array}{lll}\text { 1. Increased } & 2 \text {. Decreased } 3 \text {. No change }\end{array}$ 
4. What are the production and area for the last 5 years

\begin{tabular}{|l|l|l|l|}
\hline Crop & Year & Production (Qt) & Area (ha) \\
\hline & 2012 & & \\
\hline & 2011 & & \\
\hline & 2010 & & \\
\hline & 2009 & & \\
\hline & 2008 & & \\
\hline
\end{tabular}

5. What are the reasons for any increase in your cultivated land productivity?

1. Increased soil fertility 2. Strong extension service (improved seed supply, agrochemical use, organic fertilizer) 3. Suitable weather conditions 4. Soil and water conservation practices 5. Other, please specify

6. What are the reasons for any decrease of your cultivated land productivity?

1. Land degradation 2. Lack of timely input supply 3. Lack of oxen 4. Rainfall variability 5. Drought 6. Pests and Crop diseases 7. Other, please specify

$\begin{array}{lll}\text { 7. Do you have land use right/ownership certificate? } & 1 \text { Yes } \quad 2 \text {. No }\end{array}$

8. If your answer is yes for question 7 , has this caused you to increase your use of conservation management techniques (SWC, terracing, agroforestry, etc.)? 1. Yes 2. No

9. What is the fertility status of your cultivated land?

1. Not fertile 2. Somewhat fertile 3. fertile 4. Highly fertile

10 . What is the slope of your cultivated land?

1. Flat 2. Somewhat hilly 3. Highly sloping 4. Mountainous 5. Other, please specify

11. What type of soil is you cultivated land?

1. Black 2. Brown 3. Red 4. Other

12. What are you doing to protect land degradation and to increase the productivity of the cultivated land?

\begin{tabular}{|c|l|l|}
\hline $\begin{array}{l}\text { Land conservation } \\
\text { activities }\end{array}$ & $\begin{array}{l}\text { Individually } \\
(1=\text { Yes, 2=No })\end{array}$ & $\begin{array}{l}\text { In group (communally) } \\
(1=\text { Yes, 2=No })\end{array}$ \\
\hline 1. & & \\
\hline 2. & & \\
\hline
\end{tabular}




\begin{tabular}{|l|l|l|}
\hline 3. & & \\
\hline 4. & & \\
\hline 5. & & \\
\hline 6. & & \\
\hline 7. & & \\
\hline 8. & & \\
\hline
\end{tabular}

\section{Crops}

1. How many hectares did you farm last year?

2. What is the size of your land with improved SWC Practices in ha?

3. Do you practice crop rotation in your locality? 1 . Yes 2. No

4. What are the sequence of crop rotation?

5. What cropping patterns do you use in your farm land? 1. Monocropping 2. Mixed cropping 3. Both 4. Other, if any

6. Do you use conservation tillage practices? 1. Yes, 2. No

7. What are the crop production and its input used according to the type of crop?

\begin{tabular}{|c|c|c|c|c|c|c|}
\hline \multirow{2}{*}{$\begin{array}{l}\text { Type of } \\
\text { crop } \\
\text { produced }\end{array}$} & \multirow{2}{*}{$\begin{array}{l}\text { Size of } \\
\text { land in } \\
\text { hectare }\end{array}$} & \multirow{2}{*}{$\begin{array}{l}\text { Products } \\
\text { (Quintals, } \\
100 \mathrm{~kg} \text { ) }\end{array}$} & \multicolumn{4}{|c|}{ Utilization of inputs in percent of land area } \\
\hline & & & $\begin{array}{l}\text { Chemical } \\
\text { fertilizer }\end{array}$ & $\begin{array}{l}\text { Natural } \\
\text { fertilizer }\end{array}$ & $\begin{array}{l}\text { Improved } \\
\text { crop } \\
\text { varieties }\end{array}$ & $\begin{array}{l}\text { Local crop } \\
\text { species }\end{array}$ \\
\hline & & & & & & \\
\hline & & & & & & \\
\hline & & & & & & \\
\hline & & & & & & \\
\hline & & & & & & \\
\hline & & & & & & \\
\hline
\end{tabular}

\section{Energy Source}

1. What are the main energy sources for cooking your food, and what is the percentage of each?
a) Electricity
f) Charcoal Only 

b) Gas
g) Charcoal, Gas and Biomass
c) Electricity and Gas
h) Dung Cake
d) Firewood and Charcoal
i) Crop Residue
e) Firewood Only

2. Where do you get fire wood? Please indicate the percent of your firewood from each category.
Communally owned forest
Privately owned forest land
Naturally grown trees in the farm land
Buying fire wood

Other, specify

3. Do you use an energy efficient Stove? 1. Yes 2. No

\section{$\underline{\text { Livestock }}$}

1. What type of livestock you own and what are their number?

\begin{tabular}{|l|l|l|l|}
\hline Type of animal & Size in number & Their feeding source* & $\begin{array}{l}\text { Problems related to } \\
\text { fodder }\end{array}$ \\
\hline Ox & & & \\
\hline Cow & & & \\
\hline Sheep & & & \\
\hline Goat & & & \\
\hline Horse & & & \\
\hline Mule & & & \\
\hline Donkey & & & \\
\hline Poultry & & & \\
\hline Oee colony & & & \\
\hline
\end{tabular}

*Source of fodder $1=$ own private grazing land $2=$ co mmunal grazing land $3=$ crop residue $4=$ buying fodder $5=$ other (please specify) 


\section{Infrastructure and Markets}

1. What is the distance to all-weather roads from your home (how long does it take (hours))?

2. What is the distance of your home to the nearest school (how long does it take (hours))?

3. Do you send your children to the school? 1 . Yes 2. No

4. What is the distance to Health services from your home? (km or walking hours)

5. What is the distance to Veterinary services from your home? ( $\mathrm{km}$ or walking hours)

6. What is the distance to water source from your home? (km or walking hours)

7. What is the distance to water source from your home?

8. What is the distance to market from your home?

9. What type of agriculture output you sell in the market?

10. What is the distance to savings and credit institutions?

11. Have you borrowed money? 1. Yes 2. No

12. If the answer is NO, what is the reason? 1. Have not wanted to, 2. Denied, 3.

13. Do you owe a person or an institution more than 500 Birr? 1. Yes 2. No

14. Who are the organizations or the people you owe this money to?
1. Bank/MFI
5. Friend or neighbor
2. Government
6. Equb
3. Moneylender
7. Iddir
4. Family Member
8. Other

15. How much do you Olowe in total?

16. What are your total household savings?

17. Do you have access to Electricity? 1. Yes 2. No

18. Do you have access to Telephone? 1. Yes 2. No

19. Do you have access to piped water? 1. Yes 2. No

20. Do you have access to a radio? 1. Yes 2. No

21. Are you a member of farmers' cooperative (MPCs)? $1=$ Yes, $2=$ No

22. Is there any market linkage for selling your product? $1=$ Yes, $2=$ No

23. If your answer is No for Q22, how you can establish the market linkage? 


\section{Institutions (Social Capital)}

1. Are you member of social institutions in your village 1. Iddir, 2.Equb, 3. Religious groups, 4. Others, 5. None

2. Are you a member of the CIP? 1. Yes 2. No

3. How did you become a member of the CIP?

4. Did you participate actively to define the governance structure of your CIP? 1. Yes 2. No

5. Did you participate actively in the election of CIP leadership? 1. Yes 2. No

6. Are the bylaws agreed by the general assembly? 1. Yes 2. No

7. How do you rate the implementation of the bylaws? 1. Very weak, 2. Weak, 3. Fair, 4. Good, 5. Very Good

8. Did you participate in the identification and adoption of sustainable adaptation strategies by communities? 1. Yes 2. No

9. Do you participate actively in the implementation of the adaptation options identified by your CIP? 1. Yes 2. No

10. Do you contribute money or in kind to sustain your CIP? 1. Yes 2. No

11. What is the number of no-work days in a month?

12. How do you rate the tradition of working together in the CIP?

1. Very weak, 2. Weak, 3. Fair, 4. Good, 5. Very Good

\section{Access to Information:}

1. Is there any agricultural extension service in your locality? 1. Yes 2. No

2. Does the presence of extension services help you to improve productivity and production? 1 . Yes 2. No

3. How often do you meet and get advice from the extension agent? 1. Weekly, 2. Once in two weeks, 3. Once in three weeks, 4. Once in a month, 5.

4. Do you get important information related to agriculture and market from this information center/source? 1. Yes 2. No

5. What is your source for climate related information? 1. Radio 2. Television 3. Newspaper and magazine 4. Agriculture experts 5. Neighbors 6. Other, please specify 
6. Have you participated in skill-upgrading training to improve your knowledge about climate change adaptation? 1. Yes, 2. No

7. Did the trainings you participated in help your agricultural production?
1. Very little
2. Little
3. Moderate
4. Significant
5. Very significant

\section{Climate Change}

1. Is the current climate condition the same as it was 20 years ago in your locality?
1. Yes
2. No

2. What change has there been in daily temperature in the past 20 years?

1. Increase 2. Decrease 3. No change/constant 4. I don't know 5. Other, please specify

3. What are the local indicators that show the variability/change in temperature through time in your surroundings?

a) Frequency of occurrence of drought and floods

b) Human and animals diseases that has not been seen before

c) The emergence of new species of animals and plant in your local area

d) Changes of clothing style of the communities

e) Degradation/deterioration of rivers through time

f) Change of animal and plants/crop type

g) Other, please specify

4. What change has there been in rainfall in the past 20 years?

1. Increase 2. Decrease 3. No change 4. Change in the seasons of rainfall 5. Increase in the frequency of drought 6 . I don't know 7. Other, please specify

5. What are the local indicators that show the variability/change in rainfall through time in your surrounding?
a) Changes in cropping season
b) Changes in crop types
c) Changes in productivity
d) Other, please specify 
6. What are the 3 most important response measures you have taken, if any, to adapt and protect the problems caused due to climate change/variability in your locality?

( 1. Plowing along the contour 2. planting along the contour 3. Stone/soil bund 4. Fallowing 5. Crop rotation 6. Intercropping 7. Use of chemical fertilizer 8. Use of improved seeds 9. Preparing and use of compost 10. Agroforestry 11. Draining of Vertisols 12.Establishing protected area 13. Water harvesting 14 . Other (please specify))

7. Explain any problems that hinder the implementation of the above listed adaptation strategies and offer suggestions to solve these problems.

Thank you for your cooperation

Open Access This article is distributed under the terms of the Creative Commons Attribution License which permits any use, distribution, and reproduction in any medium, provided the original author(s) and the source are credited.

\section{References}

Byerlee D, Spielman DJ, Alemu D, Gautam M 2007 Policies to Promote Cereal Intensification in Ethiopia: a Review of Evidence and Experience. IFPRI Discussion Paper No. 707. IFPRI, Washington DC, USA, pp 37

Chambers R, Conway G (1992) Sustainable Rural Livelihoods: practical Concepts for the 21st Century, IDS Discussion Paper 296. IDS, Brighton, UK, pp 33

Conway G (1985) Agroecosystem analysis. Agr Admin 20:31-55

Conway D, Schipper ELF (2011) Adaptation to climate change in Africa: challenges and opportunities identified from Ethiopia. Glob Environ Chang 21:227-237

Entwire PM, Al-Hassan RM, Kuwornu JKM, Osei-Owusu Y (2013) Application of livelihood vulnerability index in assessming vulnerability to climate change and variability in Northern Ghana. J Environ Earth Sci 3:157-170

Ethiopian EPA (2011) Ethiopia's Climate-Resilient Green Economy (CRGE). Federal Democratic Republic of Ethiopia, Addis Ababa, Ethiopia, pp 188

Funk C, Peterson P, Lasdsfeld M, Pedreros D, Verdin J, Rowland J et al (2013) A Quasi-global precipitation time series for drought monitoring. In: (ed) U.S. geological survey data series. Vol. pp. http://chg.geog.ucsb.edu/ data/chirps.pdf

Füssel H-M (2007) Vulnerability: a generally applicable conceptual framework for climate change research. Glob Environ Chang 17:155-167

Gallopín GC (2006) Linkages between vulnerability, resilience, and adaptive capacity. Glob Environ Chang 16: 293-303

Hahn MB, Riederer AM, Foster SO (2009) The livelihood vulnerability index: a pragmatic approach to assessing risks from climate variability and change — a case study in Mozambique. Glob Environ Chang 19:74-88

Hurni H (1988) Degradation and conservation of the resources in the Ethiopian highlands. Mt Res Dev 8:123130

Hurni H (1998) Agroecological belts of Ethiopia: explanatory notes on three maps at a scale of 1:1,000,000. Soil conservation research program of Ethiopia, Addis Ababa, Ethiopia, pp 31 
IPCC (2007) Summary for policymakers. In: Solomon S, Qin D, Manning M, Chen Z, Marquis M, Averyt KB, Tignor M, Miller HL (eds) Climate change 2007: the physical science basis. contribution of working group I to the fourth assessment report of the intergovernmental panel on climate change. Cambridge University Press, Cambridge and New York

Jahnke HE and Asemanew G (1983) Ethiopian highlands reclamation study: an assessment of the recent past and present livestock situation in the Ethiopian highlands. Land Use Planning and Regulatory Department, Ministry of Agriculture and Food and Agriculture Organization, Addis Ababa, Ethiopia, pp 150

Kelly PM, Adger WN (2000) Theory and practice in assessing vulnerability to climate change and facilitating adaptation. Clim Chang 47:325-352

Maddison D (2006) The perception of and adaptation to climate change in Africa. CEEPA Discussion Paper No. 10. CEEPA, University of Pretoria, Pretoria, South Africa, pp 47

McSweeney C, Lizcano G, New M, Lu X (2010a) The UNDP climate change country profiles. Bull Am Meteorol Soc 91:157-166

McSweeney C, New M, Lizcano G (2010b) UNDP climate change country profiles: Ethiopia. Available at http:// country-profiles.geog.ox.ac.uk/index.html?country=Ethiopia\&d1=Reports In: (ed), Vol. pp

Mohan D, Sinha S (2010) Vulnerability assessment of people, livelihoods and ecosystems. WWF-India. Retrieved from CAKE http://www.cakex.org/virtual-library/3458. Accessed 01 Nov 2013

Nyssen J, Poesen J, Haile M, Moeyersons J, Deckers J (2000) Tillage erosion on slopes with soil conservation structures in the Ethiopian highlands. Soil Tillage Res 57:115-127

Parry ML, Canziani OF, Palutikov JP, van der Linden PJ, Hanson CE (2007) Technical summary. In: Parry ML, Canziani OF, Palutikov JP, van der Linden PJ, Hanson CE (eds) Climate change 2007: impacts, adaptation and vulnerability. contribution of working group II to the fourth assessment report of the intergovernmental panel on climate change. Cambridge University Press, Cambridge and New York

Sewagegn A (2011) The economic impacts of climate change on crop agriculture and the role of agricultural technologies towards better adaptation: a case in Choke Mountain watersheds of Ethiopia[Thesis]. Type. Addis Ababa University, Addis Ababa

Simane B (2011) Building resilience to climate change and green economy in mountain ecosystems of Ethiopia: Integrating research, capacity building and sustainable development activities. Proceedings of the stakeholders workshop. Debre Markos, Ethiopia, pp. 92

Simane B, Zaitchik BF, Mesfin D (2012) Building climate resilience in the Blue Nile/Abay highlands: a framework for action. Int J Environ Res Public Health 9:610-631

Simane B, Zaitchik B, Ozdogan M (2013) Agroecosystem analysis of the Choke Mountain watersheds, Ethiopia. Sustainability 5:592-616

Smakhtin V, Schipper ELF (2008) Droughts: the impact of semantics and perceptions. Water Policy 1:131-143

Smit B, Wandel J (2006) Adaptation, adaptive capacity and vulnerability. Glob Environ Chang 16:282-292

Snover AK, Whitely Binder L, Lopez J, Willmott E, Kay J, Howell D et al. (2007) Preparing for climate change: a guidebook for local, regional and state governments. ICLEI-Local Governments for Sustainability, Oakland, CA, pp 186

Sullivan C (2002) Calculating a water poverty index. World Dev 30:1195-1210

Swanson DA, Hiley JC, Venema HD, Grosshans R (2009) Indicators of Adaptive Capacity to Climate Change for Agriculture in the Prairie Region of Canada: Comparison with Field Observations. Working Paper. IISD, Winnipeg, Manitoba CA, pp 31

World Bank (2010) In: Economics of adaptation to climate change, Ethiopia. Vol. pp. https://openknowledge. worldbank.org/handle/10986/12504 License: CC BY 3.0 Unported., Washington DC

World Bank (2011) Ethiopia: climate risk factsheet. pp. 16,The World Bank, Washington DC, USA. http:// siteresources.worldbank.org/INTAFRICA/Resources/Ethiopia_Country_Note.pdf. Accessed 01 Nov 2013

Zaitchik BF, Simane B, Habib S, Anderson MC, Ozdogan M, Foltz JD (2012) Building climate resilience in the Blue Nile/Abay highlands: a role for earth system sciences. Int J Environ Res Public Health 9:435-461 